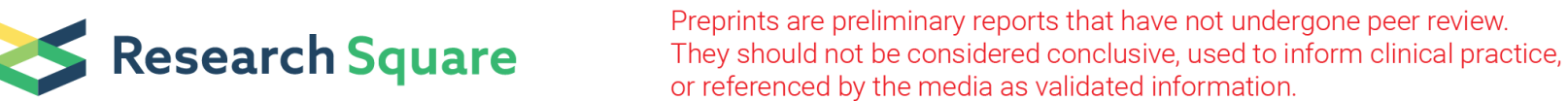

\section{Challenges Experienced by Midwives Working in Rural Communities of the Bongo District in the Upper East Region of Ghana. A Qualitative Study}

\section{Peter Adatara}

University of Health and Allied Sciences, Ho, Ghana

Philemon Adoliwine Amooba

Kwame Nkrumah University of Science and Technology, Kumasi Ghana

Agani Afaya ( $\square$ aagani@uhas.edu.gh )

University of Health and Allied Sciences, Ho, Ghana https://orcid.org/0000-0002-7918-2999

\section{Solomon Mohammed Salia}

University of Health and Allied Sciences, Ho, Ghana

Mabel Apaanye Avane

University of Health and Allied Sciences, Ho, Ghana

\section{Anthony Kuug}

University of Health and Allied Sciences, Ho, Ghana

\section{Raymond Saa-Eru Maalman}

Allied Health Institute: Orion College

\section{Confidence Alorse Atakro}

University of Health and Allied Sciences, Ho, Ghana

Irene Torshie Attachie

University of Health and Allied Sciences, Ho, Ghana

Constancia Atachie

University of Health and Allied Sciences, Ho, Ghana

\section{Research article}

Keywords: Midwives, Midwifery care, Experiences, Challenges, Ghana

Posted Date: October 6th, 2020

DOI: https://doi.org/10.21203/rs.3.rs-78724/v1

License: (c) (1) This work is licensed under a Creative Commons Attribution 4.0 International License.

Read Full License 
Version of Record: A version of this preprint was published at BMC Pregnancy and Childbirth on April 9th, 2021. See the published version at https://doi.org/10.1186/s12884-021-03762-0. 


\section{Abstract}

Intoduction

Globally, a total of 295000 women lost their lives due pregnancy and childbirth in 2017, with subSaharan Africa and South Asia accounting for approximately $86 \%$ of all maternal deaths. Currently the Maternal Mortality Ratio (MMR) in Ghana is uncceptably high with about 308 deaths/100,000 live births in 2017 and most of these maternal deaths occur less in urban areas than in rural areas. As midwives play a vital role in maternity care and in the reduction of MMR, this study therefore sought to explore and describe challenges experienced by midwives working in rural communities in the Bongo District of the Upper East region of Ghana.

Methods

A qualitative descriptive exploratory design was used to gain better insight into midwives' experiences of working and providing women-centred midwifery care in rural areas of Ghana. A total of 30 midwives providing midwifery care in rural areas of the Upper East region of Ghana for at least three years were purposefully selected for this study. Data were collected using individual semi-structured interviews and analysed through qualitative content analysis.

Results

Five main themes emerged from the data analysis. These thematic areas included inadequate infrastructure (lack of bed and physical space), lack of logistics, shortage of midwifery staff, lack of motivation, and limited in-service training opportunities.

Conclusion

The study concludes that although the rural midwives perform a multidisciplinary function in providing midwifery care in rural northern Ghana, they experience a myriad of challenges in providing midwifery care. There is the need for the Ghana Health Service and other stakeholders to motivate midwives working in rural areas through policy interventions such as rural incentive allowances, supportive supervision and in-service training opportunities for midwives in order to encourage them to accept posting to rural areas of Ghana to improve maternal and child health care.

\section{Introduction}

Maternal mortality is unacceptably high. Globally, a total of 295000 women lost their lives due pregnancy and childbirth in 2017, with sub-Saharan Africa and South Asia accounting for approximately $86 \%$ of all maternal deaths. The global maternal mortality ratio (MMR, the number of maternal deaths per 100000 live births) was estimated at 211 and since the year 2000, there have been $38 \%$ reduction in the MMR. Showing that on the average there is $2.9 \%$ decline in global MMR every year between 2000 and 2017 [1] . If the pace of progress accelerates enough to achieve the SDG target by reducing global MMR 
to less than 70 per 100000 live births, it would save the lives of at least 1,000,0000 women [1, 2]. Currently the MMR in Ghana is unacceptably high with about 308 deaths/100,000 live births in 2017 [2] and most of these maternal deaths occur less in urban areas than in rural areas due to high prevalence of skilled birth attendance (74\%) in urban areas than in rural areas (43\%) [3].

Global research has concluded that Midwives play a pivotal role in providing maternity care in rural areas in low and middle income countries [4]. Previous studies show that appropriate, accessible, and equitable birth care provided by skilled birth attendants such as midwives is a strategy that is crucial in saving the lives of pregnant women as well as preventing morbidity $[4,5,6]$. According to the International Confederation of Midwives (ICM), a midwife is recognised as a responsible and accountable professional who works in partnership with women to give the necessary support, care and advice during pregnancy, labour and the postpartum period, to conduct births on the midwife's own responsibility and to provide care for the new-born and the infant [7]

Empirical evidence shows that when midwifery care is provided by educated, trained, regulated, licensed midwives, it is associated with improved quality of care, rapid and sustained reductions in maternal and newborn mortality $[6,8]$. Evidence suggests that the deaths of women during pregnancy are generally lower in countries where most women give birth utilising the services of skilled providers, including those with midwifery skills [5]. In most sub-Saharan African countries including Ghana, birth care in rural areas are provided by trained midwives [9]. Despite the fact that midwives play important roles in providing maternal health care in the rural areas of Ghana, reports from the Ghana Health Service show out of a total 7,677 midwives, only 462 midwives are practising in the Upper East region of Ghana [10]. Although the number of trained midwives in Ghana has improved over the years, there is an inequitable distribution of midwives across the country with the rural and deprived areas such as northern Ghana being disadvantaged and affected by the inequitable distribution of health workers. Empirical studies indicate that in order to improve access to skilled midwifery care services and reduce the number and burden of maternal morbidity and mortality in rural clinics, there is the need to expand pre- and in-service training opportunities and more resources to enhance the scope and quality of the services that midwives are able to provide in rural and deprived areas $[5,11]$.

In spite of the important role midwives play in maternal health care in rural settings, few or no study has been carried out or documented about the perspectives of midwives working in rural and deprived areas of northern Ghana with regards to the challenges they experience in providing midwifery care, or what support and systems are needed to ensure that rural childbearing women and their newborns are provided with the highest attainable standard of dignified and respectful midwifery care. Most of the previous research studies carried out in the study setting were focused on the experiences of mothers utilising skilled birth care $[12,13,14,15]$. This study was aimed at exploring and describing the challenges experienced by midwives providing midwifery care in rural northern Ghana.

\section{Methods}




\section{Research Design}

The research aimed to explore and describe the challenges experienced by midwives working in the rural areas of northern Ghana. An explorative, descriptive qualitative study design was used to explored and describe experiences of midwives providing midwifery care in rural communities of northern Ghana. Understanding the challenges experienced by midwives will play a significant role in reducing maternal mortality through increased access to midwifery service provision in rural areas of Ghana.

\section{Study Setting}

The research was carried out in the Bongo District in the Upper East Rregion of Ghana. The Bongo District is one of the nine (9) districts in the Upper East Region of north Ghana. The capital is Bongo.The district was selected as the setting because it is one of the most rural and deprived districts in Ghana. The Bongo District has one District Hospital with 6 health centres located throughout the district. In the district, except for only one district hospital which has one general practitioner (medical doctor) and midwives providing skilled birth care, the rest of the maternity units in health facilities in the district are manned by midwives providing primary maternity care for women during their pregnancy and childbirth.

\section{Study Population and Sampling Strategy}

In this study, 30 registered midwives were purposefully selected based on their experiences, willingness to participate and challenges of providing midwifery care in their respective institutions in rural areas and deprived communities in the Bongo District of Upper East Region of Ghana. The researchers strived to recruit a maximum variation sample to include diverse experiences in the study.

\section{Inclusion criteria}

The inclusion criteria included:

- A registered midwife working in a rural area of Upper East Regionof Ghana for not less than three years

- Midwives who were on full-time employment during the time of data collection

\section{Exclusion criteria}

The exclusion criteria included:

- Auxillary midwives were excluded

- Midwives on postretirement employment

- Midwives on rotation or internship

- Midwives who worked for less than three years

\section{Data Collection method}


Data were collected through semi-structured interviews using a flexible interview guide to explore midwives' experiences and challenges of working in the rural areas of northern Ghana. The interview guide was developed by authors to suit the context of the study setting and to produce information which will enhance the welfare of midwives working in rural areas. Thus, participants had the opportunity to express their challenges with minimal interruption. The interviews took place in safe, quiet, comfortable, private and mutually agreed-upon locations. The individual interviews were initially planned to take place at the health facilities in the district, but after two interviews with participants, it was realised that the participants were distracted by clients accessing maternal health care services in the facilities of the participants. Some of the participants suggested their home as the most preferred venues for the individuals because those venues were free from interruptions. All the participants who agreed to take part in the research were asked to sign an informed consent after reading and receiving information about the purpose of the study. The interviews lasted between 45 and 60 minutes and were recorded and then transcribed verbatim. Also, a review of staff duty roster and case records were conducted to gain a further understanding of the extent of the experiences and challenges of a rural midwife. Data collection continued until no new information was forthcoming even with probing.

\section{Data Analysis}

A qualitative content analysis was employed to analyse data as described by Padgett [16]. There were no pre-empted themes to guide this study so the appropriate form of analysis was inductive content analysis. The researchers read and reread the transcripts several times to make meaning of midwives' views/challenges. Transcripts were coded after reading through individual sentences word by word carefully to identify words or phrases that spelled out the meaning of the sentences. Before the start of the coding process and during the coding process the first and third author coded the same interviews to identify and discuss the differences in coding to check for intercoder reliability. Similar codes were categorized to form themes and to ensure that they were representative of the midwives views, the researchers met and discussed thoroughly the themes and agreed on the themes after several deliberations.

\section{Ethical Consideration}

The Ethical Committees of the Faculty of Post Graduate Studies Committee at Nelson Mandela University (H14-HEA-NUR-30) and the Ghana Health Services approved this study. The participants chosen for interviews were provided with both verbal and written information regarding the purpose, general content and nature of the investigation.Confidentiality was supported by not providing any identifiable information such as name, age and place of employment with the transcribed interviews.

\section{Rigour}

Rigour was demonstrated through efforts made by the researchers to confirm information that was discovered and to ensure that the information accurately represents the study participants' view. To enhance the truthful representation of participants' experiences, member-checking and following-up on 
themes identified by midwives was done to confirm that the participant agreed with or understood the interpretation derived from the recorded data. The researchers also purposively selected and interviewed registered midwives who have experienced challenges in working in rural northern Ghana. The first author met the participants prior to the interview to establish rapport. Facilitative communication skills such as probing, minimal verbal responses and clarification were used to validate the meaning of communicated messages and observations. Transcripts were read several times to develop a coding framework, which was finalised through consensus among investigators. The researchers also provided a detailed description of the study setting, methodology (COREQ criteria were used) [17].

\section{Results}

Emergent and often interlinking themes were identified from the narratives obtained from midwives. Midwives' years of practice ranged from a minimum of three years to near retirement. Most of the participants were providing frontline care. Five themes emerged from the individual interview transcripts regarding the challenges experienced by midwives in delivery care to rural women;

1. Inadequate infrastructure (lack of beds and physical space)

2. Lack of logistics

3. Shortage of midwifery personnel

4. Lack of motivation

5. Limited in-service training

\section{Inadequate infrastructure (lack of beds and physical space)}

One of the key themes that emerged from data analysis was inadequate infrastructure (lack of beds and physical space) to render quality care. All the participants acknowledged that inadequate infrastructure such as rooms to accommodate many labouring women was a challenging and frustrating. They further bemoaned that lack of beds syndrome affect quality of midwifery care because women that are layed on the bare floor is difficult to nurse patients. They further expressed that cases that they could handle in the facility were referred to district hospitals due to lack of beds and these actions carried out by the midwives brought inconviences to the pregnant women and their families which may have had negative repercussion on facility deliveries. The midwives also said that due to lack of beds they have to always bend or squat to deliver care to the women and this has a lot of negative health implications such as spinal and waist pains.

"In rural areas, we have a big problem with wards and beds. Sometimes, due to inadequate rooms and beds, anytime we have more than three women in labour, we are compelled to put them on mattresses on the floor because the room can only contain three women at a time".

"In fact, I must say that working in a rural area is like a hell. ...due to lack of space, we have to refer some of them to the district hospital which at the normal circumstance should not be the case". 
"...hmmm .....it's a serious problem here (referring to a rural health facility). There are no enough beds and mattresses. Sometimes, when the expectant mothers are more than the number of beds, we put the mattresses on the floor".

\section{Lack of logistics}

All the participants expressed their frustrations due to lack of equipment and basic consumables to work with. They recounted many occasions when they could not perform the full iterative midwifery care to expectant mothers due to lack of consumables and this affected quality of midwifery care. The midwives further explained that they always have to improvise with the little resources at their disposal in other to meet the health needs of the expectant women but knowing that it wasn't the best practice. They had to improvise to safe the life of the mothers and the unborn babies. The midwives felt that they are being neglected by the healthcare managers because they make requisitions for these logusitics to be provided in order to improve quality midwifery care in the rural settings but their efforts and voices are not being heard. Below are some narrations by midwives;

"In this clinic, the challenge we face here is not only about beds and space to put the clients but also, consumables and supplies such as gloves, liquid soap, cotton and gauze to work. We have always been improvising in every procedure we perform in this clinic".

"... as I talk to you now, we do not have disposable gloves and detergents to work now. How can you work without these basic things? Sometimes, I ask myself is it because we are working in the rural area that they (referring to health care managers) do not care about us?

\section{Shortage of Midwifery personnel}

The shortage of midwives in the distraict was a major issue across the facilities as midwives lamented about this chronic shortage which affects their ability to function effectively due to work over load. Most midwives were complelled to work for 24 hours because there was no one to take over the shift for them to also have some rest. They explained that working for a whole week without rest may lead them into a stress state which will further affect their ability to deliver care care effectively.

"In this clinic, we are only three midwives manning the maternal and child health services. We currently handling the responsibilities of about five or more midwives which is making us get stressed up...".

"... we are dying here because of work. We are only two midwives and the work is just too much for us".

"I must say that we don't rest at all. We work 24 hours and sometimes, seven days a week without rest".

Most of the participants also indicated that apart from working around the clock, due to the shortages of midwives in the rural areas, many of them hardly take their annual leave as required by every worker in the public service. Some participants felt that they were exshauted due to continue care delivery without periods of breaks and this was causing burnout among them. 
"We hardly take our annual leave because of the inadequate number of midwifery staff in our facilities. I have not taken my annual leave for three years I have been posted here as a midwife".

"We are now getting tired and weaker because we have no time to rest, and we do not even take annual leaves like our colleagues in other parts of the country."

\section{Lack of motivation}

All the participants in this study acknowledged that in spite of the workload on midwives working in rural areas of northern Ghana, they were not given any incentive such as rural incentive allowances to enable them to put up their best. The midwives felt on noticed and not recognised by the efforts they put in the delivery of quality maternal and child health services in the communities.

"I must say that it appears no one recognises our work in this remote area where there is a lot of workloads. I have never been paid any allowance since I started working in this remote area for almost five years now".

Some of the participants indicated that although there are other health personnel such doctors who are given rural incentive allowances as a form of motivation for them to accept posting to rural and deprived areas of northern Ghana, midwives are not given any allowance.

"I feel we (midwives) are unfairly treated by the Ghana Health Service or government because we are rather working in the most deprived and rural areas of northern Ghana. Doctors do not work in these areas, and yet we are not given any rural incentive allowances. But, medical doctors who are rather not working in these areas are paid 10 per cent of their salary as rural incentive allowances as motivation for them to accept posting to northern Ghana".

Participants believed that because there is no incentive given to midwives in rural areas in northern Ghana, most of their colleagues who were posted to the rural areas refused to report to their post.

"I must say that because the government does not give us any rural incentives or any form of motivation, some of our colleagues (midwives) who were posted here to work refused to report or assume duty. Some reported, but because there was no motivation given to us, they asked for a transfer to other regions".

Most of the participants indicated that they were compelled to work at rural areas even though they were not given any rural allowances as a form of motivation because they did not have the opportunity to leave the place.

"....As for me, I am still working here because I did get the opportunity to leave here. If there were jobs in the towns and cities that can employ us, I would have left here a long time ago. But, there are no jobs, and our managers would not also agree for us to go on transfer".

Almost all participants indicated that if the government wants midwives to accept posting to rural and deprived areas in the northern part of Ghana, there is the need to implement rural incentive allowances for 
midwives to encourage them to accept posting to rural areas to reduce maternal mortality.

"....If the government wants midwives to accept posting to these remote areas, then the government should introduce rural incentive allowances for midwives to encourage them to accept posting to rural areas like here (the study setting) like the government has done for medical doctors".

Although most participants felt not motivated by management and the government, a few however, admitted that promotions and study leave with pay were granted much faster for midwives working in rural areas than those working in the developed towns and cities. Some midwives still expressed great concern that though the study processes are much faster, they are not able to still further their education due to staff shortage.

".....But I must say that our only advantage and motivation for working in these rural areas is that our promotions are faster than our colleagues in the towns and cities."

"One good thing for working in these rural areas is that we can be allowed to go to school for further studies with pay when we work for at least two to three years..but the disadvantage is that when you are the only one or two in the facility, it is always very difficult to leave the facility when there is no one to offer care for the labouring mothers.

\section{Limited in-service training opportunities}

All the participants acknowledged that there were limited in-service training opportunities for midwives working in rural communities to improve their knowledge and skills like their counterparts who are working in the towns and cities.

"It is a disadvantage of working in rural areas in the north. As we are working here, we are only able to attend few in-service training courses, unlike our colleagues who are in the cities who have the opportunity to attend lots of workshops training all the time".

Participants pointed out that although they occasionally attend workshop training organised by Ghana Health Services and other institutions due to shortage of midwives in rural areas, many of them did not have the opportunity to attend those workshops.

"I must acknowledge that workshops have been organised by Ghana Health Service and other bodies, but due to our number (a few staff) we are unable to attend most of those workshops. I, for instance, had to miss three to four workshops because anytime there is a workshop and I planned to attend I will end up being alone in my health facility, and you cannot close down the facility and attend the workshop".

Participants reported that apart from the fact that they are unable to attend many workshops organised by the Ghana Health Service and other organisation to improve their knowledge and skills, they also do not have the opportunity for effective mentorship and coaching by senior and experienced midwives in the rural areas. 
"....Hmmm, our problems are just too many. When you are posted here, you are just on your own. There are no senior or more experienced midwives here to mentor or coach us..."

"As for this place, when you are posted here, you are your own boss. No senior midwife to teach you or mentor you. We are always on duty alone or with one person, so who will teach the other?"

\section{Discussion}

Midwives are important maternal healthcare providers in the rural areas of Ghana. This study explored and described the challenges experienced by midwives who provide maternal healthcare to childbearing women and their newborns in rural and deprived areas of northern Ghana. The results of this study showed that one of the major challenges experienced by midwives working in rural northern Ghana was inadequate infrastructure (lack physical space and beds). Inadequate infrastructure such as wards and beds to accommodate many labouring women at the same time was reported as a major challenge hindering the quality of midwifery care provided to women in rural areas of Ghana. The finding of this study is consistent with previous studies which identified inadequate wards and hospital beds as major challenges affecting the quality of midwifery care in rural communities $[11,18]$. The current study finding is also similar to a recent study conducted in rural northern Ghana where there was no physical space to admit women attending for child birth services [19]. In resource constraint settings, women in labour will have to queue in health facilities for child birth services due overcrowding and also share beds with with other women during and after childbirth [20]. This is usually attributed to the lack of physical space and beds in the facilities [20]. In some instances where there are limited beds in the facilities women would have to lie on floors or on bare mattresses after childbirth [20,21]. Although infrastructural development in the health sector in Ghana has improved over the years, rural and deprived areas of the country still lack adequate infrastructure to accommodate the increasing number of patients and clients seeking healthcare in the facilities. There is therefore a need for Government and stakeholders to invest in infrastructural development in the rural and deprived areas since the majority of the maternal deaths in Ghana occur in the rural and hard to reach areas.

The shortage of midwifery staff in the rural areas of Ghana remains an important issue of interest to policy makers and Governments. The current study revealed that understaffing was a challenge experienced by midwives in the low resource settings. According to the participants, adequate staffing is necessary for effective and adequate care delivery in order to improve maternal and child healthcare. The current study found that understaffing was a serious challenge affecting quality midwifery care in the rural areas of northern Ghana and to help breach this gap most midwives had to work overtime whiles some don't even take their annual leave. The finding of this study is consistent with findings of previous studies conducted globally and in sub-Saharan Africa, where insufficient personnel were the most important reasons for poor conditions at work cited by midwives $[14,22]$. For instance, a study conducted by Bremnes, Wiig, Abeid and, Darj in 2018 to explores the challenges midwives face in their day-to-day practice at a health facility in Tanzania found that one of the challenges experienced by midwives was shortage of midwifery personnel in the health facilities which led to an excessive workload resulting in 
difficulties with providing adequate care [23]. Similarly other studies indicates that inadequate staffing levels and increasing workload among health professionals was challenge across both rural and urban settings $[4,24,25,26]$. Also a study finding concerning African countries documented that inadequate staffing and excessive overtime work was found to compromise womens safety and the midwifery staff as well [27]. The over demanding workload could place midwives in an ethical dilemma on how to prioritize care: in Malawi nurse-midwives mentioned of the daily problem of indecisions of who to care for; whether the newborn or the mother, or even another mother or another newborn [28]. The World Health Report in 2006 identified Ghana among 36 countries in SSA facing health workforce crisis [29] which necessitated government interventions through the Ministry of Health to address a myriad of health workforce challenges especially nurses and midwives. Recently out of about 115650 employed public sector health workers 58\% were nurses and midwives [30, 31]. From 2008 to 2018 there has been a remarkable increase in the nursing workforce of about 370\% [30]. Nonetheless, empirically, there exists a lingering shortage of nurses and midwives in most hospitals and clinics across the country especially in rural settings [31, 32]. As in recent times over 40,000 trained nurses and midwives have been unemployed between 2016 to 2019 whiles health facilities across the country are in dire need of these professionals. Due to the extended credit facility agreement between the government of Ghana and the International Monetary Fund (IMF) with its associated austerity measures, most of the graduated nurses from 2016 and 2018 could not be immediately employed [32]. We recommend that in developing a new human resource policy and strategy for the health workforce, it would be imperative for the Ministry of Health $(\mathrm{MOH})$ to embark on a comprehensive health labour market analysis paying attention to the midwifery labour market dynamics to generate robust evidence to support need-based training of midwives which will meet the population health needs and avert this chronic shortage of midwifery staff in the country especially in the rural areas of Ghana.

Lack of motivation was identified as another challenge that midwives experienced in the delivery of maternity care in the rural settings. The midwives felt that their efforts and sacrifices in delivering quality maternity care in order to improve maternal and child health to avert morbidity and mortality among mothers and their children was overlooked and unappreciated. They argued that some cadre of health professionals were rather motivated by government through rural incentive allowances but they were not considered fit to also receive the allowances. The midwives felts neglected and their concerns were not addressed. Our study finding is similar to a study by Bremnes, Wiig, Abeid and Darj [23] where midwives felt they were not motivated to provide quality care. In the World Health report on improving healthcare performance, the WHO emphasized that supportive supervision contributes to a positive performance by health workers $[33,34]$. When healthcare workers are not motivated by the employer, they turn to lack courtesy to patients, provide poor care and failure to treat patients at the appropriate time [35]. It is documented that the patients health outcomes are therefore critically dependent on the nurses' and midwives motivation. Therefore, providing training on supportive management methods for supervisors or hospital managers is a documented measure to increase the level of motivation in the workplace. Health facilities that at least provide minimum allowances, tend to have the health professionals well motivated to provide quality care to patients that are more content with the care delivered to them [36]. 
We also recommend that the rural incentive allowance policy should be to revised to include all essential healthcare workers in the rural areas of Ghana but not only one cadre of healthcare wokrfore without considering the major key players in providing quality care in these areas.

Lack of basic medical equipment or logistics to work with was one of the major challenges confronting midwives working in the rural areas of northern Ghana. The midwives were frustrated and could not deliver the full iterative midwifery care due to lack of consumables to work with which affected quality care delivery. Midwives had to improvise with the insufficient basic medical equipment at their disposal in order to meet the health needs of the expectant women but knowing that it wasn't the best practice. This study finding is consist with a study conducted in Tanzania with midwives reported that they had inadequate supply of medical equipment to provide quality care for women [23]. A recent study in Ghana also reported inadequate medical equipment for childbirth services in rural northern Ghana [19]. The inadequacy of basic medical supplies contravenes the quality statements (statement 8) of the WHO, stipulating for a positive experience for all women in the period of pregnancy, childbirth and postpartum [37]. Though this lack of basic medical supplies affects the patients receiving care it also exposes the midwives in contracting infections due to inadequate basic protective equipment. In the absence of safe working environment, such as water for hand washing, sharps disposal, and basic protective medical supplies such as gloves, and also limited access to Post Exposure Prophylaxis (PEP) which left some midwives highly exposed to HIV infection in the workplace $[38,39,40]$. In order to protect the patients and midwives from an hazadious working environment there is therefore an urgent need for the government to invest in resources including better-equipped maternity units with medical supplies to provide maternal health care services to women to further prevent maternal and newborn deaths and disabilities in rural areas of Ghana.

limited in-service training opportunities to improve their knowledge and skills were reported in this study as challenges experienced by midwives working in rural areas of Ghana. Global research literature reported similar findings that community midwives were struggling for survival in rural areas due to lack of limited in-service training opportunities to improve their knowledge and skills [4]. According to the WHO, lack of adequate pre- and in-service midwifery education and professional development impacts negatively on preparation for the midwifery role and the building of personal autonomy, resulting in low levels of skill and confidence in many countries particularly in rural areas of the country affecting their ability to provide quality care $[9,41]$. There is the need for supportive supervision and mentoring at work, improved professional development programmes, workshops, access to higher education training opportunities.

\section{Limitations}

A key limitation of the study is social desirability bias, as the midwives might not report their real experience as it occurred. Also, the sample size for this study was relatively small and the study covered only one district in Ghana. The findings may, therefore, not be representative of the experiences and challenges all rural midwives in the county. Nonetheless, this is an important study that explored the 
experiences and challenges of rural midwives which will guide human resource management policies and decisions in the health sector of Ghana.

\section{Conclusion}

The study concluded that although the rural midwife performs a multidisciplinary function in providing midwifery care in rural northern Ghana, they experience a myriad of challenges in providing midwifery care in the rural areas of northern Ghana affecting their ability to provide quality midwifery care. There is the need for the Ghana Health Service and other stakeholders to provide effective supportive supervision and mentoring, improved professional development programmes, workshops, access to higher education training opportunities for midwives working in rural areas to improve upon their knowledge and skills to provide the highest attainable standard of dignified and respectful midwifery care. Policy interventions such as rural incentive allowances should be implemented by the Ghana Health Service and other stakeholders in health for midwives working in rural areas to encourage them to accept posting to rural areas of Ghana to improve maternal health care and further prevent maternal and newborn deaths and disabilities.

\section{Abbreviations}

MMR: Maternal mortality rate

WHO: World Health Organisation

PEP: Post Exposure Prophylaxis

COREQ: Consolidated criteria for reporting qualitative research

IMF: International Monetary Fund

MOH: Ministry of Health

ICM: International Confederation of Midwives

SSA: Sub-Saharan Africa

SDG: Sustainable Development Goals

\section{Declarations}

\section{Competing interests}

The authors have declared that no competing interests exist

\section{Consent for publication}


Not applicable

\section{Availability of data and materials}

The datasets used and/or analyzed during the current study are available from the corresponding author on reasonable request

Supplementary file: Interview guide

\section{Funding}

The study received no funding

\section{Ethics approval and consent to participate}

The research had ethical approval from the Faculty of Post Graduate Studies Committee at Nelson Mandela University (H14-HEA-NUR-30).The ethical principles of respect for persons, beneficence and justice were adhered to throughout the study. Written informed consent was obtained from all participants prior to conducting the semi-structured interviews.

\section{Authors' contributions}

PA and AA conceived the idea and conceptualised the study. PA and collected the data. PA, PAA,AA,SMS, MAA and AK analysed the data. PA, AA RSM and CAA drafted the manuscript, then ITA and CA reviewed the manuscript. All authors read and gave final approval for the version to be published, and agreed to be accountable for all aspects of the work

\section{Acknowledgement}

Authors wish to thank all the midwives in the Bongo district for their cooperatinn and partipation in the study

\section{References}

1. World Health Organization. World health statistics 2020: monitoring health for the SDGs sustainable development goals. World Health Organization; 2020. Available from; https://apps.who.int/iris/bitstream/handle/10665/332070/9789240005105-eng.pdf.

2. World Health Organization. . Trends in maternal mortality 2000 to 2017: estimates by WHO, UNICEF, UNFPA, World Bank Group and the United Nations Population Division. World Health Organization. 2019. Available from; https://apps.who.int/iris/handle/10665/327595.

3. Apanga PA, Awoonor-Williams JK. Maternal death in rural Ghana: a case study in the upper East Region of Ghana. Frontiers in public health. 2018;6:101. 
4. Filby A, McConville F, Portela A. What prevents quality midwifery care? A systematic mapping of barriers in low and middle income countries from the provider perspective. PloS one. 2016;11(5):e0153391.

5. Pan American Health Organization. Toolkit for strengthening professional midwifery in the Americas. 3rd edition. Montevideo:

6. Koblinsky M, Matthews Z, Hussein J, Mavalankar D, Mridha MK, Anwar I, Achadi E, Adjei S, Padmanabhan P, van Lerberghe W, Lancet Maternal Survival Series steering group. Going to scale with professional skilled care. The Lancet. 2006;368(9544):1377-86.

7. International Confederation of Midwives. International Definition of the ICM. 2017

8. Stanton C, Blanc AK, Croft T, Choi Y. Skilled Care At Birth In The Developing World: Progress To Date And Strategi Es For Expanding Coverage. Journal of biosocial science. 2007;39(1):109.

9. World Health Organisation. Midwives voices, midwives realities. Findings from a global consultation on providing quality midwifery care. Geneva. WHO; 2016.

10. Ghana Health Service (GHS). "Reproductive and Child Health Unit (Public Health Division) Annual Report”, 2016. Accra: GHS; 2016.

11. United State. Agency for International Development (USAID). The Emerging Midwifery Crisis in Ghana: Mapping of Midwives and Service Availability Highlights Gaps in Maternal Car USAID, 2006.

12. Adatara P, Strumpher J, Ricks E. A qualitative study on rural women's experiences relating to the utilisation of birth care provided by skilled birth attendants in the rural areas of Bongo District in the Upper East Region of Ghana. BMC Pregnancy and Childbirth. 2019;19(1):195.

13. Sarfraz M, Hamid S. Challenges in delivery of skilled maternal care-experiences of community midwives in Pakistan. BMC pregnancy and childbirth. 2014;14(1):59.

14. Adatara P, Afaya A, Baku EA, Salia SM, Asempah A. Perspective of traditional birth attendants on their experiences and roles in maternal health care in rural areas of northern ghana. International journal of reproductive medicine. 2018.

15. Afaya A, Yakong VN, Afaya RA, Salia SM, Adatara P, Kuug AK, Nyande FK. A qualitative study on Women's experiences of Intrapartum nursing Care at Tamale Teaching Hospital (TTH), Ghana. Journal of Caring Sciences. 2017;6(4):303.

16. Padgett DK. Qualitative and mixed methods in public health. USA: SAGE publications; 2011.

17. Tong A, Sainbury P, Craiq J. Consolidated criteria for reporting qualitative research (COREQ): a 32 item checklist for interviews and focus groups. Int J Qual Health Care. 2007;19(6):349-57.

18. Sarfraz M, Hamid S. Challenges in delivery of skilled maternal care-experiences of community midwives in Pakistan. BMC pregnancy and childbirth. 2014;14(1):59.

19. Dalinjong PA, Wang AY, Homer CS. Are health facilities well equipped to provide basic quality childbirth services under the free maternal health policy? Findings from rural Northern Ghana. BMC health services research. 2018;18(1):959. 
20. Bohren MA, Vogel JP, Hunter EC, Lutsiv O, Makh SK, Souza JP, Aguiar C, Coneglian FS, Diniz AL, Tunçalp Ö, Javadi D. The mistreatment of women during childbirth in health facilities globally: a mixed-methods systematic review. PLoS medicine. 2015;12(6):e1001847.

21. Banchani E, Tenkorang E. Implementation challenges of maternal health care in Ghana: the case of health care providers in the tamale Metropolis. BMC Health Serv Res. 2014;14(1):7.

22. Kafulafula UK, Hami M, Chodzaza E. The challenges facing nurse-midwives in working towards Safe Motherhood in Malawi. Malawi Medical Journal. 2005;17(4):125-7.

23. Bremnes HS, Wiig ÅK, Abeid M, Darj E. Challenges in day-to-day midwifery practice; a qualitative study from a regional referral hospital in Dar es Salaam, Tanzania. Global health action. 2018;11(1):1453333.

24. Rahmani Z, Brekke M. Antenatal and obstetric care in Afghanistan -a qualitative study among health care receivers and health care providers. BMC Health Services Research. 2013; 13; 166-175. doi: 10.1186/1472-6963-13-166 PMID: 23642217

25. Kwast BE, Bentley J. Introducing confident midwives: midwifery education-action for safe motherhood. Midwifery. 1991; 7; 1; 8-19. PMID: 2011093

26. Floyd L. Helping midwives in Ghana to reduce maternal mortality. African Journal of Midwifery and Women's Health. 2013; 7; 1; 34-38.

27. Pettersson KO. Major challenges of midwifery in Africa. British Journal of Midwifery. 2007; 15; 8; 470- 474.

28. Bream KDW, Gennaro S, Kafulafula U, Mbweza E, Hehir D. Barriers to and facilitators for newborn resuscitation in Malawi, Africa. Journal of Midwifery and Women's Health. 2005; 50; 4; 329-334.

29. World Health Organization. The world health report 2006: working together for health. World Health Organization; 2006.

30. Ghana Health Service. Human resource annual report - 2018. Accra: Ghana Health Service; 2019.

31. Asamani JA, Amertil NP, Ismaila H, Francis AA, Chebere MM, Nabyonga-Orem J. Nurses and midwives demographic shift in Ghana-the policy implications of a looming crisis. Human resources for health. 2019;17(1):32.

32. Asamani JA, Amertil NP, Ismaila H, Akugri FA, Nabyonga-Orem J. The imperative of evidence-based health workforce planning and implementation: lessons from nurses and midwives' unemployment crisis in Ghana. Human Resources for Health. 2020;18(1):1-6.

33. Uduma $\mathrm{O}$, Galligan $\mathrm{M}$, Mollel $\mathrm{H}$, et al. The impact of a human resource management intervention on the capacity of supervisors to support and supervise their staff at health facility level. Hum Resour Health. 2017;15:57.

34. World Health Organization. The world health report 2000: Health systems: improving performance. Geneva: World Health Organization; 2000.

35. Franco LM, Bennett S, Kanfer R, et al. Determinants and consequences of health worker motivation in hospitals in Jordan and Georgia. Soc Sci Med. 2004;58:343-355. 
36. Tibandebage P, Kida T, Mackintosh M, Ikingura J. Can managers empower nurse-midwives to improve maternal health care? A comparison of two resource-poor hospitals in Tanzania. The International journal of health planning and management. 2016;31(4):379-95.

37. Standards for improving quality of maternal and newborn care in health facilities. Geneva: World Health Organization; 2016.

38. Turan JM, Bukusi EA, Cohen CR, Sande J, Miller S. Effects of HIV/AIDS on Maternity Care Providers in Kenya. Journal of Obstetric, Gynecologic, \& Neonatal Nursing. 2008; 37; 5; 588- 595.

39. Taylor LC, Fair CD, Nikodem C. Working conditions and perspectives among South African health workers. African Journal of Midwifery and Women's Health. 2011; 5; 4; 176-180.

40. Hussein J, Phoya A, Ansong Tornui J, Okiwelu T. Midwifery practice in Ghana and Malawi: influences of the health system In: Reid L. editor. Freedom to practise: An international exploration of midwifery practice. Churchill Livingstone Elsevier: London; 2007. 75-99.

41. Walker D, Lannen B, Rossie D. Midwifery practice and education: Current challenges and opportunities. OJIN: The Online Journal of Issues in Nursing. 2014;19(2):4.

\section{Supplementary Files}

This is a list of supplementary files associated with this preprint. Click to download.

- INTERVIEWGUIDE.docx 